\title{
Dairy cow feeding space requirements assessed in a Y-maze choice test
}

\author{
F. C. Rioja-Lang, ${ }^{\star 1}$ D. J. Roberts, $†$ S. D. Healy, $\ddagger$ A. B. Lawrence, $†$ and M. J. Haskell† \\ ${ }^{*}$ Prairie Swine Centre, Box 21057, 8th Street East, Saskatoon, Saskatchewan, Canada, S7H 5N9 \\ †Scottish Agricultural College, King's Buildings, West Mains Road, Edinburgh, EH9 3JG, United Kingdom \\ ¥St. Mary's College, University of St. Andrews, South Street, St. Andrews, KY16 9JP, United Kingdom
}

\begin{abstract}
The effect of proximity to a dominant cow on a lowranking cow's willingness to feed was assessed using choice tests. The main aim of the experiment was to determine the feeding space allowance at which the majority of subordinate cows would choose to feed on high-palatability food (HPF) next to a dominant cow rather than feeding alone on low-palatability food (LPF). Thirty Holstein-Friesian cows were used in the study. Half of the cows were trained to make an association between a black bin and HPF and a white bin and LPF, and the other half were trained with the opposite combination. Observations of pair-wise aggressive interactions were observed during feeding to determine the relative social status of each cow. From this, dominant and subordinate cows were allocated to experimental pairs. When cows had achieved an HPF preference with an $80 \%$ success rate in training, they were presented with choices using a Y-maze test apparatus, in which cows were offered choices between feeding on HPF with a dominant cow and feeding on LPF alone. Four different space allowances were tested at the HPF feeder: $0.3,0.45,0.6$, and $0.75 \mathrm{~m}$. At the 2 smaller space allowances, cows preferred to feed alone (choices between feeding alone or not for $0.3-$ and $0.45-\mathrm{m}$ tests were significantly different). For the 2 larger space allowances, cows had no significant preferences (number of choices for feeding alone or with a dominant). Given that low-status cows are willing to sacrifice food quality to avoid close contact with a dominant animal, we suggest that the feeding space allowance should be at least $0.6 \mathrm{~m}$ per cow whenever possible. However, even when space allowances are large, it is clear that some subordinate cows will still prefer to avoid proximity to dominant individuals.
\end{abstract}

Key words: feeding behavior, Y-maze, choice, dominance

Received September 11, 2011.

Accepted February 28, 2012.

${ }^{1}$ Corresponding author: Fiona.Lang@usask.ca

\section{INTRODUCTION}

Feed intake, particularly DMI, is the main contributor to the volume of milk produced by dairy cows. It is economically important, therefore, for producers to maximize feed intake across the whole herd, which may also benefit cattle health and welfare. Fence line feeding, or strap feeding, is designed to allow all cows to feed at the same time. It is also the most common method used in freestall or freestall-housed dairies. It is generally assumed that, as long as all animals within the herd consume sufficient feed within a 24 -h period, the feeding area need not accommodate all cows at the same time. However, at certain times of day, access to the feed has a high motivational value and, as dairy cows live within a hierarchical social structure, dominant animals can monopolize resources.

Cows prefer to feed at certain times of day (Grant and Albright, 2001; Cook et al., 2004; DeVries et al., 2004), sometimes referred to as peak feeding times, which generally occur when fresh feed is delivered (DeVries and von Keyserlingk, 2006) and often coincide with return from the milking parlor. These periods are when most cows are present at the feed bunk and levels of aggression and competition peak (DeVries et al., 2003). A limited feeding area most likely favors cows that have high social rank. Cook et al. (2004) suggested that dominant cows sort fresh feed, and that low-ranking cows with low feed access may be forced to alter daily activity patterns and feed at the feed bunk only after the dominant cows have fed. Hosseinkhani et al. (2008) suggested that cows that are unable to access the feed bunk at peak feeding times may not maintain adequate nutrient intake to meet their energy requirements. Therefore, providing equal access to fresh feed may be particularly important in reducing the variation in diet quality consumed by the cows (Endres et al., 2005). Nutritionists attribute subclinical acidosis and reduced performance to erratic feeding behavior and intake by cattle (Shwartzkopf-Genswein et al., 2003). The incidence of acidosis may also be increased due to the design of facilities that encourage some cows to sort and consume the concentrate portion of the ration. Research indicates that lactating dairy cows demon- 
strate higher degrees of feed sorting against longer forage particles and for smaller grain concentrate particles when fed a low forage diet (DeVries et al., 2007). Regardless of the cause for sorting, this behavior can be problematic, especially for high-risk cows, as it reduces the buffering capacity in the rumen and increases the risk of acidosis occurring. Because the susceptibility of dairy cows to acidosis appears to be highest for cows in early lactation (Penner et al., 2007), they should be most affected by competition at the feed bunk.

Given a standard feeding space allowance, subordinate cows will choose to feed alone rather than next to a dominant cow (Rioja-Lang et al., 2009). Subordinate cows continue to choose to feed alone even when they are made to trade off the feed quality to be able to do so (Rioja-Lang et al., 2009). This led us to consider how varying space allowances would affect the subordinate cows' choices, ultimately allowing us to make more specific recommendations for housing regulations. The Y-maze test presents 2 options at equal distances from the entry of the maze starting position and usually involves animals being taught to anticipate a particular treatment if they enter one arm or the other of the maze. An animal is generally deemed as preferring an option if it spends more time with it, chooses it more often, or has a shorter latency to approach it (Bateson, 2004). The assumptions made when using the Y-maze choice test are that animals make choices that are in their own best interests and that understanding animals' preferences will help us to improve their welfare (Frazer and Mathews, 1997).

The main aim of this work was to determine the feeding space allowance at which the majority of subordinate cows would change their choices from feeding alone to feeding next to a dominant individual, if that dominant individual was present beside the high-palatability food (HPF). We predicted that subordinate cows would choose to feed on low-palatability food (LPF) rather than feeding on HPF near a dominant cow when the feeding space was low (i.e., spaces that are commonly found in the industry). However, we also predicted that this preference would reverse by increasing the feeding space allowance.

\section{MATERIALS AND METHODS}

\section{Animals and Housing}

Thirty mid- to late-lactation (DIM $=218 \pm 91.7$; mean $\pm \mathrm{SD}$ ) Holstein-Friesian cows of high genetic merit, split into 3 groups of 10, were used in this study. Half of the cows were multiparous (parity $=4.2 \pm$ 1.9 ; mean $\pm \mathrm{SD}$ ) and half were primiparous, with an average daily milk yield of $22.0 \mathrm{~kg} / \mathrm{cow}$ per day. All cows were housed in a freestall shed at the SAC Dairy Research Centre (Dumfries, Scotland). Each group of 10 cows was separated from the rest of the herd $24 \mathrm{~h}$ before the experiment began and housed in a separated area of the freestall housing within the main shed, where they had access to feed and water. After testing sessions, cows were returned to the main freestall area, where they had access to a grass silage-based TMR, which was formulated to provide adequate nutrients for maintenance and milk production. The cows were not fed any additional concentrates during milking. Fresh feed was delivered once a day (while the cows were in the testing arena) and they generally had access to it within $1 \mathrm{~h}$ of their normal feeding time.

\section{Test Procedure and Testing Arena}

All testing was carried out between the hours of 0800 and $1200 \mathrm{~h}$. After morning milking, the group of 10 cows was moved to a large, straw-bedded holding pen situated next to the test pen. The cows remained in this holding pen with free access to water and space to lie down but with no access to feed until the testing sessions were complete. For testing, cows were moved individually, by a handler, from the holding pen and were allowed to walk down the length of the passage $(\sim 30 \mathrm{~m})$ toward the test pen. The animals were given gentle encouragement if they did not make their way in the correct direction. Two handlers were present during all sessions, wore the same color of overalls, and stood in the same positions during each test (outside the test area).

The Y-maze was inside the test arena (Figure 1) and consisted of a single alley (1.2 m long) with 2 arms (each $3.65 \mathrm{~m}$ long), 1 to the left and 1 to the right. At the end of each arm was either a black or white feed bin $(0.75 \mathrm{~m} \times 0.55 \mathrm{~m} \times 0.58 \mathrm{~m})$ and a sheet of plywood painted the corresponding color and mounted on the wall $(0.95 \mathrm{~m} \times 0.60 \mathrm{~m})$. Both boards were visible to the cow as she entered the Y-maze. The walls of the test pen were made of brick and solid wood so that animals in the pen were visually isolated from pen-mates and other distractions in the shed. The arena was classified as having 2 separate zones (not formally separated) so that the location of the cows could be recorded during testing (Figure 1).

\section{Dominance Testing}

Animals were allocated to pairs consisting of a dominant and subordinate animal (relative to each other). To assess the dominance of each cow, we constructed 


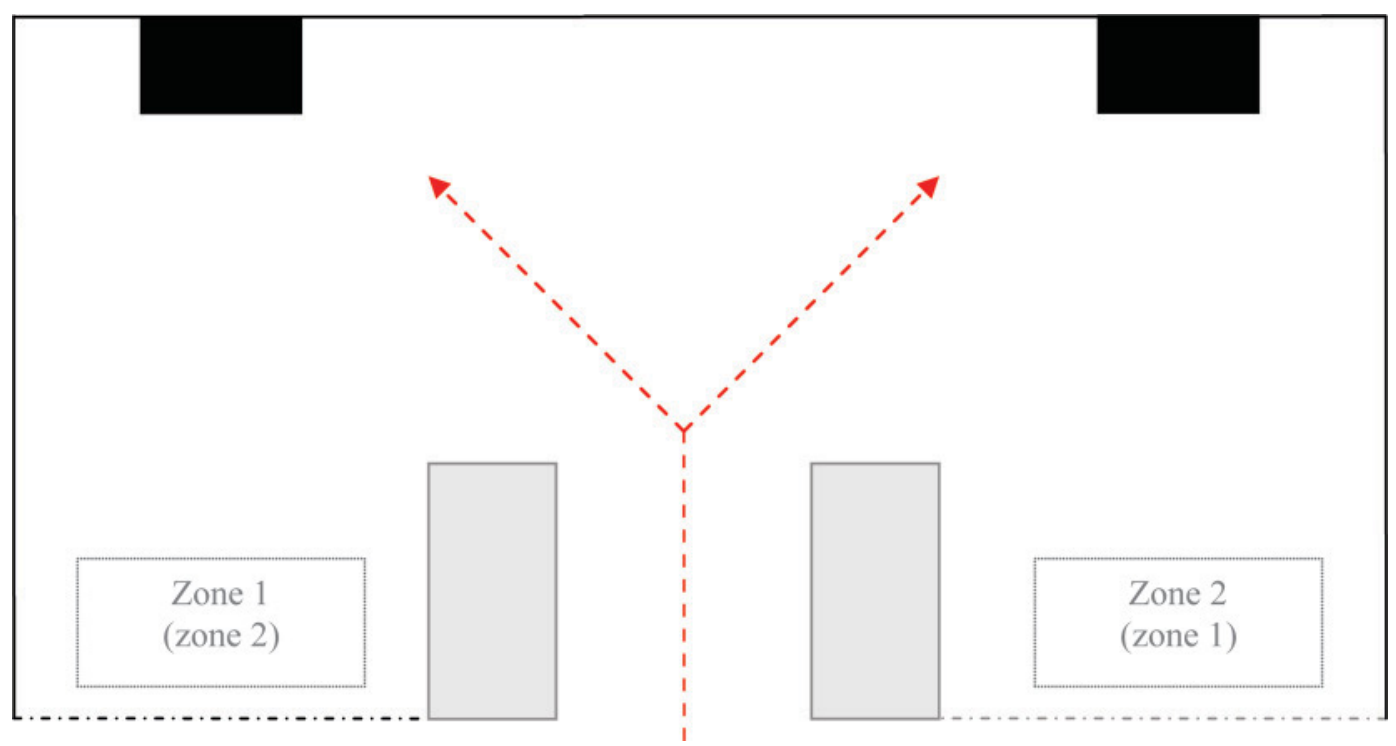

Figure 1. Diagram of test arena, including starting entrance, 2 zones, and position of feed bins. NB. Although this is referred to as a Y-maze, there are no formal divisions of the arms of the Y. Color version available in the online PDF.

an index from interactions observed at the feed bunk in the freestall area. Displacements were recorded at a post-and-rail feed barrier of limited space during the 30-min period after the delivery of fresh feed and after the afternoon milking for 5 consecutive days. These 2 recording periods were selected as they have been shown to be the times when most cows - and the highest level of competition - are present at the feed face (DeVries et al., 2003). A displacement was noted when a cow's head (actor) came in contact with a cow that was feeding (reactor), resulting in the reactor withdrawing its head from the feed face, as described in Huzzey et al. (2006). The number of displacements per cow was used to measure the competitive behavior of cows at the feed face. These observations were used to calculate an "index of success" from agonistic interactions of each individual cow using the method described by Mendl et al. (1992). This was calculated by dividing the number of cows that an individual was able to displace by the number of cows that an individual was able to displace plus the number of cows that were able to displace the individual, all multiplied by 100 . This method has previously been used to assign dominance in several dairy cattle and pig studies (Mendl et al., 1992; DeVries et al., 2004; DeVries and von Keyserlingk, 2006; RiojaLang et al., 2009).

From within each group of 10 animals, cows were assigned a rank from 1 to 10 , with 10 being the most dominant. To maximize the dominance between pairs, cows were paired $10-5,9-4,8-3, \ldots$, and so on. In cases where observations of spontaneous interactions did not resolve dominance in specific pairs of cows, these pairs were presented with a line of concentrate feed in an open space to finally resolve relative rank.

\section{Training Procedure}

The training phase consisted of 4 consecutive days. Half of the cows were trained to associate a black feed bin as containing HPF and a white bin as containing LPF. The other half of the group was trained with the opposite combination. The HPF was a concentrate pellet and the LPF was a mix of rolled barley $(82 \%)$ and soy $(18 \%)$. These feeds were chosen because they vary in palatability but have similar levels of $\mathrm{ME}$ and $\mathrm{CP}$. The concentrate pellet contained molasses, which tastes sweet, and dairy cows are known to like it. Concentrates are highly valued by cows and are therefore a cause of competition and aggression (Herlin and Frank, 2007). The feed chosen was also familiar to these cows, because it was a component of their regular grass silage TMR (formulated to provide adequate nutrients for maintenance and milk production). It was given in a $0.5-\mathrm{kg}$ meal because this is what they received in the milking parlor as they were being milked. All cows were trained, even though only the subordinate cows were going to be tested, so that all of the cows were familiar with the arena and equipment.

For each training session, the cows were individually brought into the test arena and presented, in a randomized order, with 1 bin of either HPF or LPF, in either the black or white bin, on the right or left hand side of the pen. Each cow had 2 nonconsecutive training sessions per day for $4 \mathrm{~d}$, each of which lasted for a period 
of about $5 \mathrm{~min}$ (this was the average length of time it took to consume the $0.5-\mathrm{kg}$ meal).

After the $8 \mathrm{~d}$ of training, we tested whether the animals had learned the association between the feed quality and the color of the bin. Each cow was presented with both bins together, 1 containing HPF and 1 containing LPF (1 in each arm of the "Y") and their first choice was considered to be the bin from which they took the first mouthful of feed. Cows were removed from the maze either once they had finished the feed from the bin of their choice or when 5 min had elapsed. When cows had achieved an HPF preference with an $80 \%$ success rate in training, they were able to proceed to the final choice tests.

\section{The Experimental Procedure: Choice Test Between Feeding Alone or Next to a Dominant Cow}

To determine whether subordinate cows chose to feed alone or whether they did so because the dominant cow physically blocked them from feeding at a trough, we presented the trained cows with a bin of HPF at the end of each arm of the Y-maze. A dominant cow was also present feeding at 1 of the feed bins. Each cow was tested 4 times over $4 \mathrm{~d}$, and the location of the dominant cow was randomized over the trials. To determine choices, we split the test arena into 2 zones (Figure 1). These zones represented the side the dominant cow was occupying (1) and the unoccupied area (2); the amount of time that a subordinate cow spent in each zone was recorded.

\section{Choice Test Between Feed Quality and Proximity to a Dominant Cow}

In the experimental choice test, subordinate cows were presented with a feed bin containing HPF with the dominant cow present and a feed bin containing LPF without another cow present. Four different treatments were tested, in which we used 4 sizes of feed bins: 0.6, $0.9,1.2$, and $1.5 \mathrm{~m}$ for a pair of cows, which equates to $0.3,0.45,0.6$, and $0.75 \mathrm{~m} / \mathrm{cow}$. These distances ranged from the smallest, which was very likely to result in subordinates choosing to feed alone on LPF (as found by Rioja-Lang et al., 2009), to the largest space, 0.75 $\mathrm{m}$. This can be compared with the standard recommended by the British Standard Code of Practice at the time this research was conducted, which stated that cattle of 500 to $700 \mathrm{~kg}$ of BW require 600 to $700 \mathrm{~mm}$ at the feed face; however, if food is constantly available, as in ad libitum systems, these widths may be reduced by as much as $75 \%$ (Defra, 2005). The distances chosen were intended to allow dominant and subordinate cows to feed comfortably next to each other. Each cow was presented with a choice test once a day for $4 \mathrm{~d}$. The arm of the Y maze in which the dominant cow was feeding and the order of presentation of the space allowances were randomized across all cows.

\section{Data Collection and Statistical Analyses}

For each choice test, the number of times an individual cow chose each option was recorded. Sign tests were used to test for a significant difference between the number of times an option was chosen $(P<0.001)$. Wilcoxon signed rank tests were used to test the significance of the difference between the choices made over the different space allowances. Each test was videorecorded.

\section{RESULTS}

It took 18 training sessions for the 12 subordinate test cows to achieve the specified training criteria of 8 correct choices out of 10 in consecutive sessions. One pair from each group of 5 pairs that did not meet the criteria was dropped from the study. In the testing period with the dominant cow present, cows chose to feed alone on the LPF significantly more than they chose to eat with the dominant cow at the $0.3-$ and $0.45-\mathrm{m}$ feeding spaces (Table 1). For the 2 larger space allowances, we found no significant difference between the number of choices for feeding alone or with a dominant cow $(P$ $>0.05$ and $P>0.05$, respectively).

For the smallest space allowance $(0.3 \mathrm{~m})$, most of the test cows chose to feed alone on LPF rather than

Table 1. Preferences of subordinate cows feeding alone or next to a dominant cow at 4 space allowances in a Y-maze choice test (sign tests) ${ }^{1}$

\begin{tabular}{|c|c|c|c|c|c|}
\hline $\begin{array}{l}\text { Space } \\
\text { allowance } \\
\text { (m) }\end{array}$ & $\begin{array}{l}\text { Cows } \\
\text { (no.) }\end{array}$ & $\begin{array}{c}\text { Feed with } \\
\text { dominant/HPF }\end{array}$ & $\begin{array}{l}\text { Equal } \\
\text { choice }\end{array}$ & $\begin{array}{c}\text { Feed } \\
\text { alone/LPF }\end{array}$ & $P$-value \\
\hline 0.30 & 12 & 0 & 1 & 11 & $<0.001$ \\
\hline 0.45 & 12 & 1 & 3 & 8 & $<0.05$ \\
\hline 0.60 & 12 & 3 & 4 & 5 & $>0.05$ \\
\hline 0.75 & 12 & 5 & 2 & 5 & $>0.05$ \\
\hline
\end{tabular}

${ }^{1} \mathrm{HPF}=$ high-palatability feed; LPF $=$ low-palatability feed. 


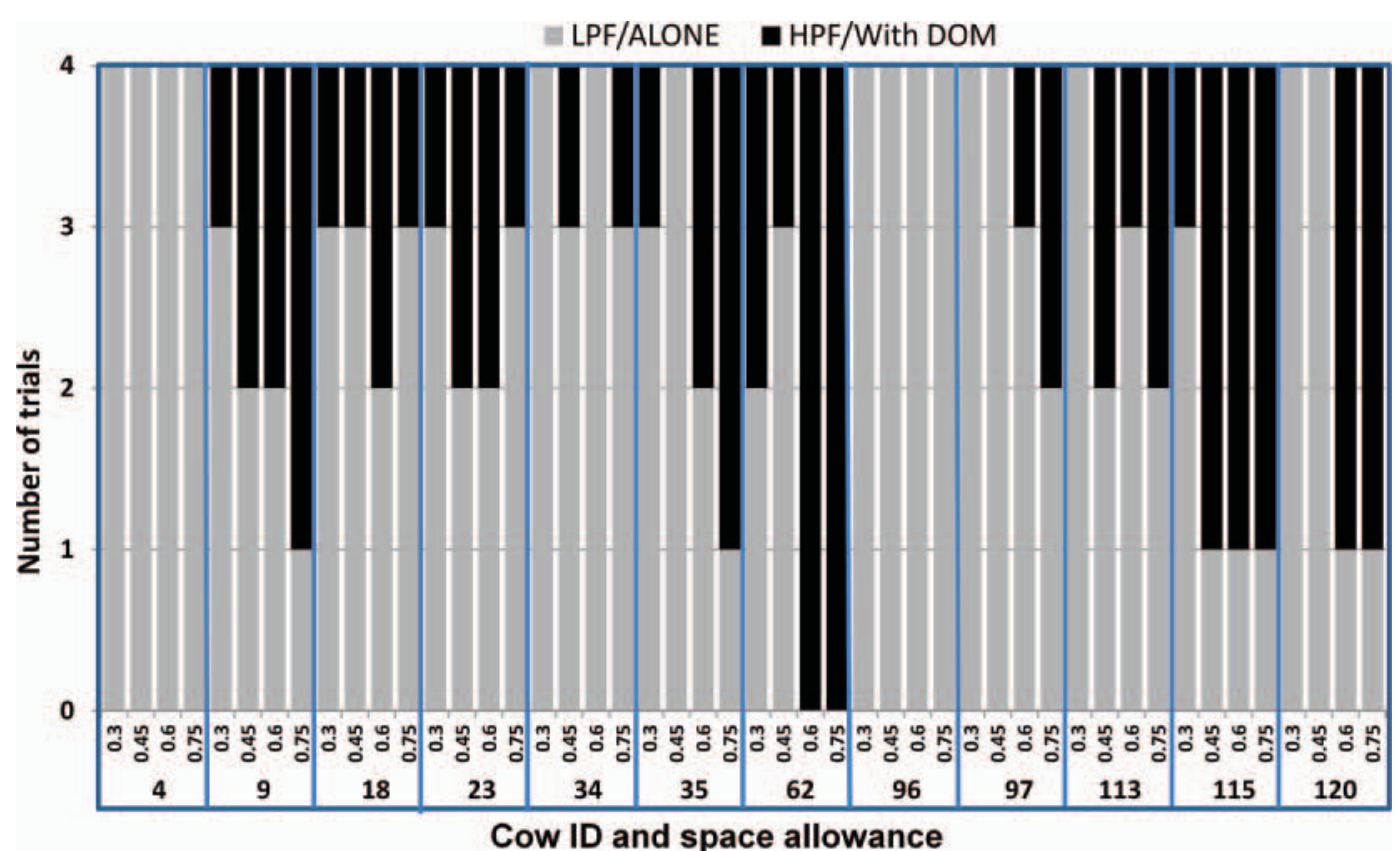

Figure 2. The choices of individual cows for feeding alone or feeding with the dominant cow at 4 feeding space allowances: $0.3,0.45,0.6$, and $0.75 \mathrm{~m} . \mathrm{LPF} / \mathrm{ALONE}=$ feeding alone on low-palatability food; HPF/with DOM = feeding on high-palatability food next to a dominant cow. Color version available in the online PDF.

next to a dominant cow (Figure 2). Once the space allowance exceeded $0.45 \mathrm{~m}$, subordinate cows showed no preference for eating LPF alone or HPF next to a dominant cow $(P>0.05)$.

\section{Time Spent in Zones of Arena}

Overall, of the different space allowances, subordinate cows spent $39 \%$ of their time standing alone in the test arena and $61 \%$ standing in the same side as the dominant cow. It appears, then, that even though a subordinate cow did not feed next to a dominant cow, she may, in some instances, have been blocked from the feed bin instead of actively choosing to feed alone.

\section{DISCUSSION}

When space allowances at feed troughs were small $(<0.45 \mathrm{~m})$, cows preferred to feed alone on LPF than to feed on HPF next to a dominant cow. Even when the feeding space was increased to $0.75 \mathrm{~m}$, cows did not switch to preferring to feed from the HPF. Choices became more variable and more cows did choose to feed on the HPF as space allowance increased; however, no preference, or acceptance of feeding next to a dominant cow, was noted at the higher space allowances. Perhaps a more consistent result would have been observed if the test cows were earlier in lactation; that is, they may be more likely to access the higher quality of feed due to increased pressure to attain greater nutrient requirements, regardless of the social pressure they face. Information is lacking on whether high-yielding cows (under greater metabolic stress resulting from high levels of milk yield) respond differently from low-yielding cows to changes in space allowance. One study by Fregonesi and Leaver (2002) investigated this issue by comparing varying space allowances of 2 housing systems and for high- and low-yielding cows. They found no evidence that high- and low-yielding cows responded differently to changes in space allowance, and they suggested that housing requirements for the 2 groups are similar. It would be interesting to repeat this experimental design using cows of differing yield potentials.

Our data are consistent with the findings of DeVries et al. (2004) that cows increased the distance from their nearest neighbor when provided with more space at the feeder, leading to reduced frequency of aggressive interactions and increased feeding. Stolba (1985) reported that increasing trough lengths for feeding pigs decreased the extent to which the food could be defended, allowing subordinates access to feed without being in close contact with dominants. Proximity to dominants at feeding time appears to be an important consideration for animals with low social status.

If feeding space is limited, increased competition among cows at the feeder may lead to some cows modifying their feeding times to avoid aggressive interactions (Miller and Wood-Gush, 1991). A study by DeVries et 
al. (2004) tested whether increasing the space availability at the feed bunk (either 0.5 or $1.0 \mathrm{~m} / \mathrm{cow}$ ) improved access to feed and reduced social competition. The results showed that when animals had access to more space, $57 \%$ fewer aggressive interactions were observed while feeding. The reduced aggressive behavior consequently allowed cows to increase feeding activity throughout the day (particularly during the first 90 min after the delivery of fresh feed). During this period, cows with access to more feeding space increased time at the feeder by $24 \%$, and this effect was strongest for subordinate cows. If subordinate cows are forced to feed after preferred peak feeding times, they may compromise their nutritional intake and thus be less productive. By providing more space at the feed bunk, more cows may feed more effectively and efficiently. The potential for increasing access to food for all of the individuals within a herd should increase feed intake and decrease feeding rate. Therefore, reducing the level of competition at the feed bunk should be a priority for dairy producers.

In the UK, dairy cows are generally housed for around 6 mo of the year over the winter period; however, systems in which cows are housed continuously throughout the year are becoming more common as cows can be fed high levels of concentrate feed more easily when they are housed (Haskell et al., 2006). Continuously housed systems are common in parts of North America. At present, housing regulations contain very few specific requirements. The UK recommendation from the Department for Environment, Food and Rural Affairs (Defra) is that if animals are expected to feed simultaneously, the feed bunk required per cow should be dependent upon the size of the animals (Defra, 2005). For example, cows weighing between 500 and $700 \mathrm{~kg}$ require a feed bunk of at least 60 to 70 $\mathrm{cm}$. If, however, feed is available $24 \mathrm{~h} / \mathrm{d}$, the feed bunk allowance can be reduced by as much as $75 \%$, leaving a space allowance of 15 to $17.5 \mathrm{~cm} / \mathrm{cow}$ (a space that is smaller than the hip width and body width of Holstein dairy cows (Enevoldsen and Kristensen, 1997). North American recommendations also suggest $60 \mathrm{~cm}$ (24 in; Grant and Albright, 2001; National Farm Animal Care Council, 2009), but those results suggest that subordinate cows may not always present themselves at the feed bunk at this space allowance. Due to the increase in continuous housing, it is necessary to house cattle in the most practical (for stockmen) and comfortable (for cows) way possible. It is also necessary to recommend more concise housing regulations.

Preference testing provides a novel approach to highlighting specific problems that subordinate animals are confronted with at the feed bunk (see also Rioja-Lang et al., 2009). As far as we are aware, a very small number of studies have used the Y-maze testing method with cattle (Grandin et al., 1994; Hosoi et al., 1995; Prescott et al., 1998; Pajor et al., 2003) and never before to investigate the effect of social dominance at the feed bunk. Successful learning performance has previously been reported in cows (e.g., Pajor et al., 2003; Arnold et al., 2007), supporting the effectiveness of this type of approach with farm animals. This experimental technique could also be used to identify different physical and environmental factors that low-status cows use to make their feeding decisions; for example, the introduction of dividers, different group compositions, and so on. To maximize feed intake, and subsequently milk production, it is important to provide a suitable feeding environment for all individuals within the herd.

\section{CONCLUSIONS}

Low-status cows prefer to feed alone than next to a dominant animal, particularly when provided a space allowance of $<0.6 \mathrm{~m}$ per cow. We recommend, therefore, that space allowance on farms should be sufficient for all cows within a herd to have at least $0.6 \mathrm{~m} / \mathrm{cow}$ to accommodate the needs of all cows. Higher space allowances would increase the motivation of low-ranking cows to access fresh feed, which could improve their nutritional status.

\section{ACKNOWLEDGMENTS}

Financial support for this experiment was provided by the Scottish Government. We thank the technical and farm staff at SAC Dairy Research Centre, Crichton Royal Farm, particularly Ainsley Bagnall, David Bell, and John Dickinson.

\section{REFERENCES}

Arnold, N. A., K. T. Ng, E. C. Jongman, and P. H. Hemsworth. 2007. The behavioral and physiological responses of dairy heifers to tape-recorded milking facility noise with and without a pretreatment adaptation phase. Appl. Anim. Behav. Sci. 106:13-25.

Bateson, M. R. 2004. Mechanisms of decision-making and the interpretation of choice tests. Anim. Welf. 13:115-120.

Cook, N. B., K. V. Nordlund, and G. R. Oetzel. 2004. Environmental influences on claw horn lesions associated with laminitis and subacute ruminal acidosis in dairy cows. J. Dairy Sci. 87:E36-E46.

Defra. 2005. Action on animal health and welfare: Housing the modern dairy cow. In Reducing Injuries in Dairy Cattle (CD-ROM). Defra, London, UK.

DeVries, T. J., K. A. Beauchemin, and M. A. G. von Keyserlingk. 2007. Dietary forage concentration affects the feed sorting behavior of lactating dairy cows. J. Dairy Sci. 90:5572-5579.

DeVries, T. J., and M. A. G. von Keyserlingk. 2006. Feed stalls affect the social and feeding behavior of lactating dairy cows. J. Dairy Sci. 89:3522-3531.

DeVries, T. J., M. A. G. von Keyserlingk, and D. M. Weary. 2004. Effect of feeding space on the inter-cow distance, aggression, and 
feeding behavior of free-stall housed lactating dairy cows. J. Dairy Sci. 87:1432-1438.

DeVries, T. J., M. A. G. von Keyserlingk, D. M. Weary, and K. A. Beauchemin. 2003. Measuring the feeding behavior of lactating dairy cows in early to peak lactation. J. Dairy Sci. 86:3354-3361.

Endres, M. I., T. J. DeVries, M. A. G. von Keyserlingk, and D. M. Weary. 2005. Short communication: Effect of feed barrier design on the behavior of loose-housed lactating dairy cows. J. Dairy Sci. 88:2377-2380.

Enevoldsen, C., and T. Kristensen. 1997. Estimation of body weight from body size measurements and body condition scores in dairy cows. J. Dairy Sci. 80:1988-1995.

Frazer, D., and L. R. Mathews. 1997. Preference and motivation testing. Pages 157-173 in Animal Welfare. M. C. Appleby and B. O. Hughs, ed. CAB International, Wallingford, UK.

Fregonesi, J. A., and J. D. Leaver. 2002. Influence of space allowance and milk yield level on behaviour, performance and health of dairy cows housed in strawyard and cubicle systems. Livest. Prod. Sci. $78: 245-257$.

Grandin, T., K. G. Odde, D. N. Schutz, and L. M. Behrns. 1994. The reluctance of cattle to change a learned choice may confound preference tests. Appl. Anim. Behav. Sci. 39:21-28.

Grant, R. J., and J. L. Albright. 2001. Effect of animal grouping on feeding behavior and intake of dairy cattle. J. Dairy Sci. 84(E. Suppl.):E156-E163.

Haskell, M. J., L. J. Rennie, V. A. Bowell, M. J. Bell, and A. B. Lawrence. 2006. Housing system, milk production, and zero-grazing effects on lameness and leg injury in dairy cows. J. Dairy Sci. 89:4259-4266.

Herlin, A. H., and B. Frank. 2007. Effects of protective gates at concentrate feed stations on behavior and production in dairy cows: A brief note. Appl. Anim. Behav. Sci. 103:167-173.

Hosoi, E., D. M. Swift, L. R. Rittenhouse, and R. W. Richards. 1995. Comparative foraging strategies of sheep and goats in a T-maze apparatus. Appl. Anim. Behav. Sci. 44:37-45.

Hosseinkhani, A., T. J. DeVries, K. L. Proudfoot, R. Valizadeh, D. M. Veira, and M. A. G. von Keyserlingk. 2008. The effects of feed bunk competition on the feed sorting behavior of close-up dry cows. J. Dairy Sci. 91:1115-1121.

Huzzey, J. M., T. J. DeVries, P. Valois, and M. A. G. von Keyserlingk. 2006. Stocking density and feed barrier design affect the feeding and social behavior of dairy cattle. J. Dairy Sci. 89:126-133.

Mendl, M., A. J. Zanella, and D. M. Broom. 1992. Physiological and reproductive correlates of behavioural strategies in female domestic pigs. Anim. Behav. 44:1107-1121.

Miller, K., and D. G. M. Wood-Gush. 1991. Some effects of housing on the social behavior of dairy cows. Anim. Prod. 53:271-278.

National Farm Animal Care Council (NFACC). 2009. Code of practice for the care and handling of dairy cattle. Accessed May 6, 2012. http://www.nfacc.ca/codes-of-practice/dairy-cattle.

Pajor, E. A., J. Rushen, and A. M. B. de Passille. 2003. Dairy cattle's choice of handling treatments in a Y-maze. Appl. Anim. Behav. Sci. 80:93-107.

Penner, G. B., K. A. Beauchemin, and T. Mutsvangwa. 2007. Severity of ruminal acidosis in primiparous Holstein cows during the periparturient period. J. Dairy Sci. 90:365-375.

Prescott, N. B., T. T. Mottram, and A. J. F. Webster. 1998. Relative motivations of dairy cows to be milked or fed in a Y-maze and an automatic milking system. Appl. Anim. Behav. Sci. 57:23-33.

Rioja-Lang, F. C., D. J. Roberts, S. D. Healy, and M. J. Haskell 2009. Dairy cows trade-off feed quality with proximity to a dominant individual in Y-maze choice tests. Appl. Anim. Behav. Sci. 117:159-164.

Shwartzkopf-Genswein, K. S., K. A. Beauchemin, D. J. Gibb, D. H. Crews, D. D Hickman, M. Streeter, and T. A. McAllister. 2003. Effect of bunk management on feeding behavior, ruminal acidosis and performance of feedlot cattle: A review. J. Anim. Sci. 81(E. Suppl. 2):E149-E158.

Stolba, A. 1985. Minimising social interference during feeding in pig groups. Page 460-461 in Vol. 2, Proc. 19th Int. Ethol. Conf., Toulouse, France. 